\title{
PAIN MANAGEMENT IN GERMAN CANCER PATIENTS
}

\section{RESULTS OF A CROSS-SECTIONAL ONLINE SURVEY ON CANCER-RELATED BACKGROUND AND BREAKTHROUGH PAIN}

\section{Michael A. Ueberall}

\section{ABSTRACT}

OBJECTIVES: Assessment of pain management quality in German cancer patients under real-life conditions.

METHODS: Nationwide German cross-sectional online survey of patients with cancer pain (CP) between February 1st to June 30th, 2017 with a standardized electronic cancer pain questionnaire to assess cancer-related background (BGCP) and breakthrough (BTCP) pain characteristics and treatment approaches. Use of predefined algorithms to assess adequate treatment (AT), medical undertreatment (UT) and malpractice (MP).

RESULTS: Participation of 5.576 patients with BGCP, $47.4 \%$ with BTCP. UT and/or MP (either isolated or in combination) occurred in $52.5 / 71.3 \%$ of BGCP/BTCP-patients. Overall, only $37.1 \%$ of patients presented formally with an adequate pain management. UT/MP had a significant impact on reported pain intensities and painrelated suffering. Overall wellbeing in adequately treated patients was reported as either "very good", "good", "satisfying" or "adequate" in $77.1 \%$, vs. $52.1 \%$ in patients with UT, $30.5 \%$ with MP, and $14.7 \%$ with a combination of UT and MP. The odds ratio for UT/MP-patients reporting their wellbeing as either "inadequate" or even "insufficient" vs. those treated adequately was 19.4 (95\%-Cl: 16.2-23.3), those for MP 7.7 (6.2-9.5), and for UT 3.1 (2.7-3.6; $\mathrm{p}$ for each comparison $<0.001)$.

CONCLUSIONS: Adequate pain management of cancer pain patients in Germany is still the exception rather than the rule. UT/MP are frequent and affect 5/10 BGCP and 7/10 BTCP patients with devastating consequences on affected individuals in comparison to those treated adequately.

Correspondence address: Michael A. Ueberall IFNAP
Pain treatment ( $\square$ adequate, undertreatment, $\square$ malpractice, $\square$ combination)

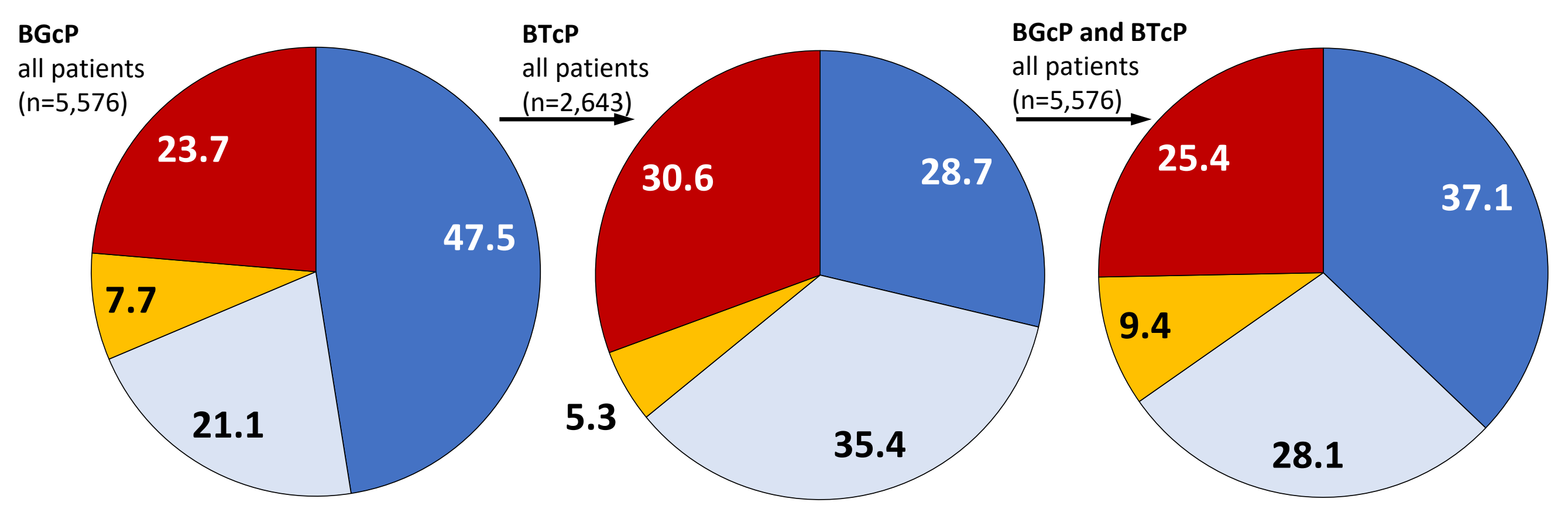

Average background cancer pain (BGCP) intensity
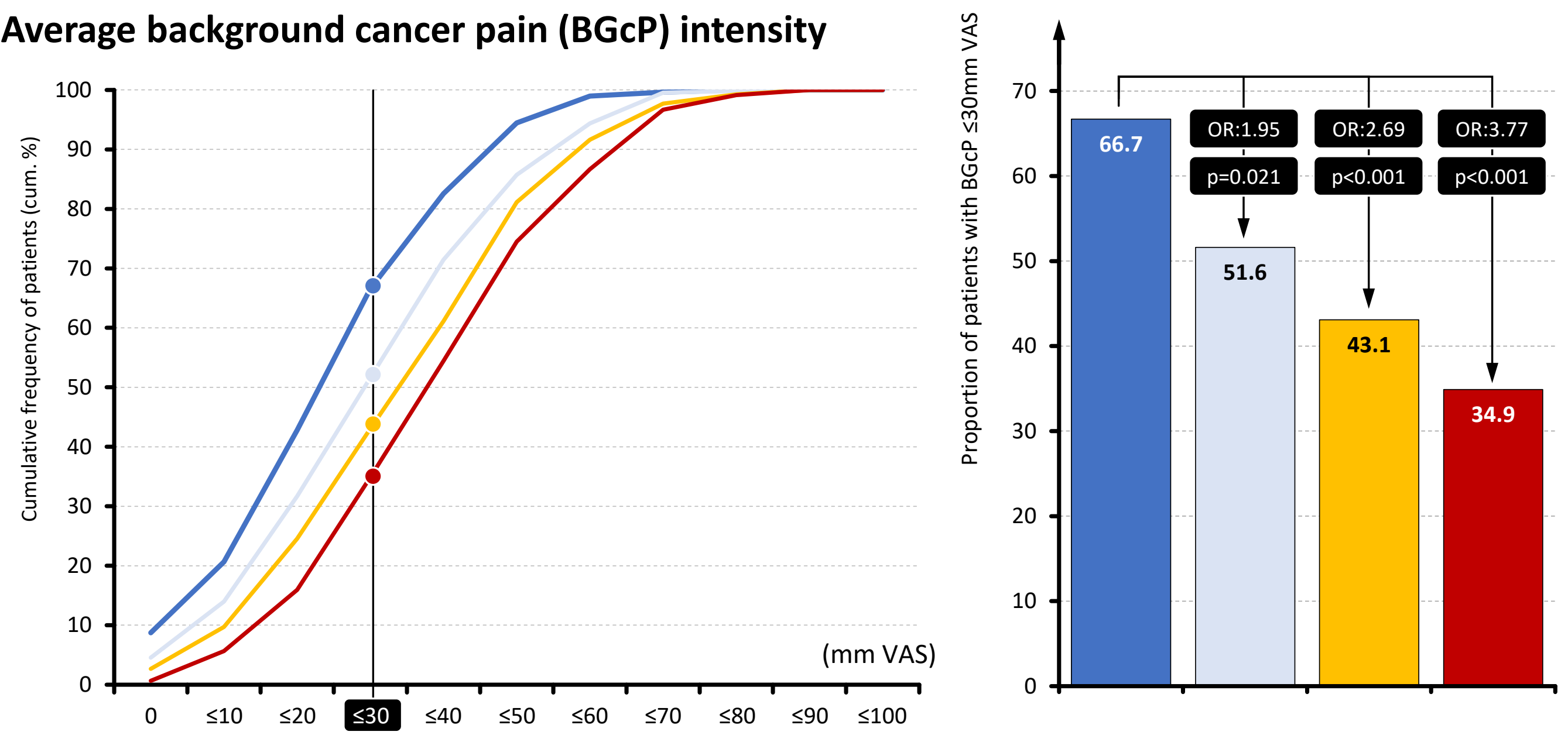

Overall wellbeing (N/VRS $)_{6}$

Relative frequency of patients (\%)

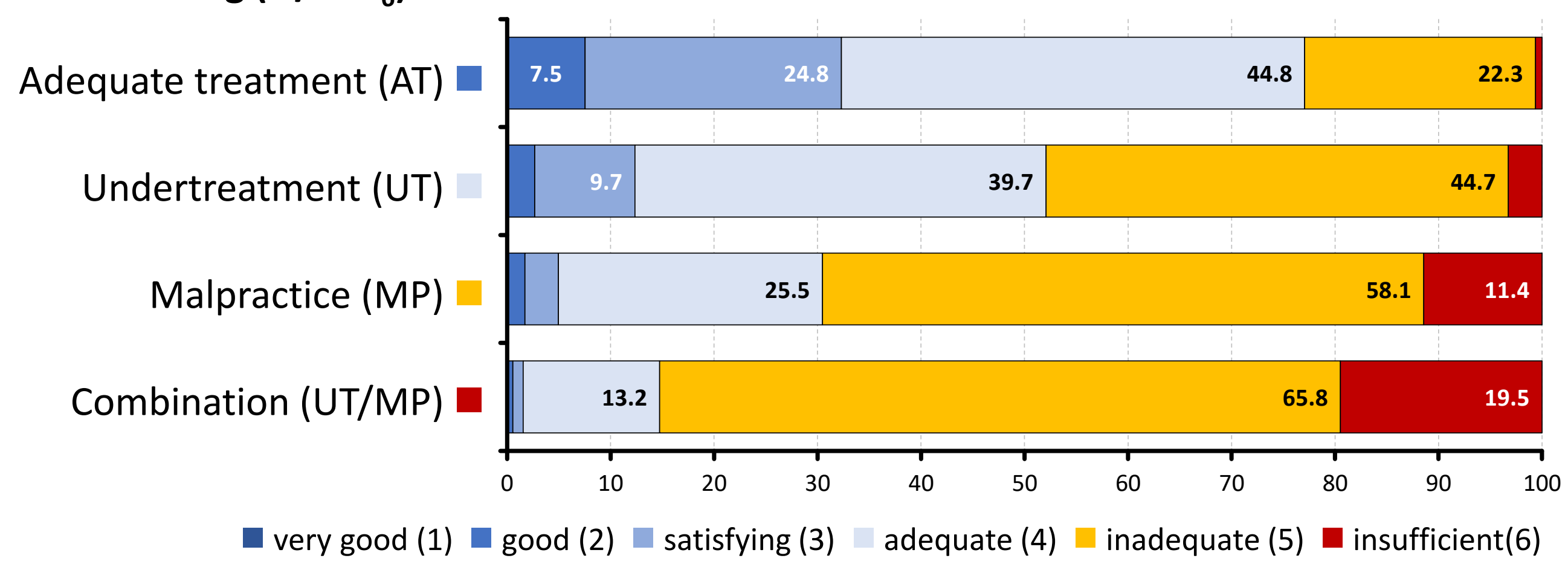

\section{Breakthrough cancer pain (BTcP) treatment approaches}

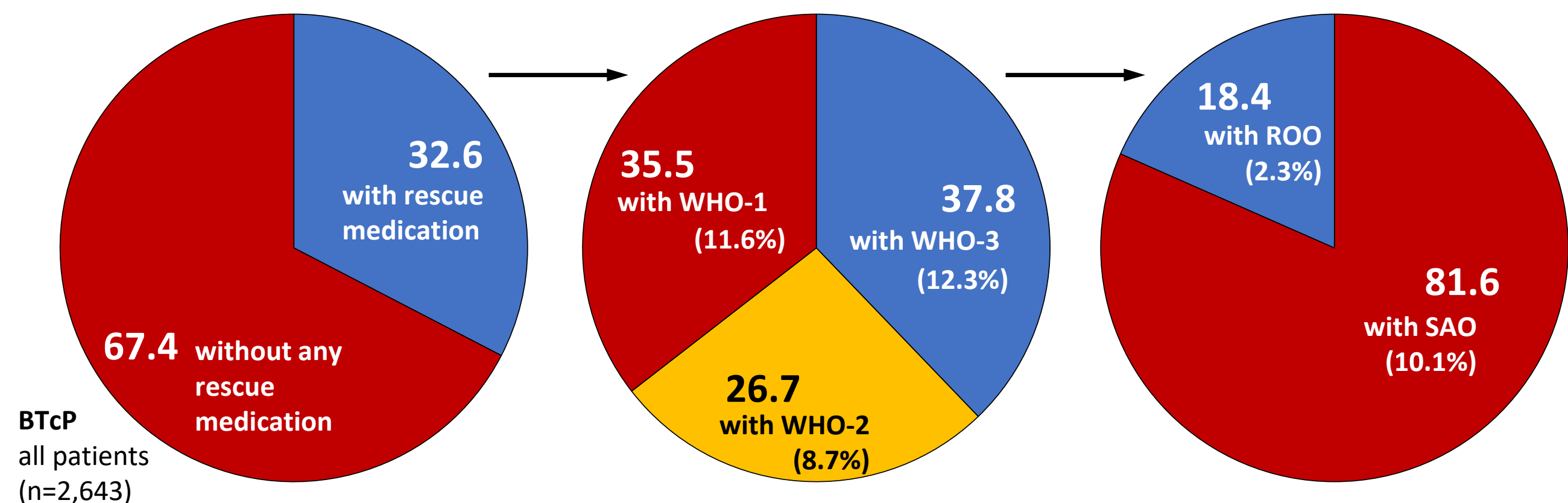

